\title{
Advanced geotechnical monitoring technology to assess ground support effectiveness
}

\author{
LP Gélinas Agnico Eagle Canada Inc., Canada \\ V Falmagne Agnico Eagle Canada Inc., Canada \\ B Bédard Agnico Eagle Canada Inc., Canada \\ O Matte Université Laval, Canada
}

\begin{abstract}
Deformation at the surface of excavations in hard rock often occurs on a millimetre scale, which means the movements cannot be readily detected through visual inspection. These slight rates of deformation can lead to cracking, bulking, wedges and even loss of material that may go unnoticed or be deemed unimportant until significant rehabilitation is needed. The impact of such deformation on ground support capacity over time is difficult to assess quantitatively. Other than visual inspections, traditional excavation monitoring technologies typically entail point measurements, such as with extensometers, prisms or convergence measurement systems. The scanning and surveying of specific excavation cross-sections are also used. The authors of this paper have tested a new technology for underground monitoring. GroundProbe's Geotech Monitoring LiDAR (GML) system has millimetre-range accuracy and measures the rate of deformation at the rock surface with high precision in each pixel of a $360^{\circ}$ image. The system can measure the rate of deformation of ground support elements and the surrounding rock or shotcrete surface at any given time, in any drive, intersection or stope entry. This technology was tested in two different hard rock underground environments through a process of experimentation and validation. The GML system was used to monitor large critical infrastructure with shotcrete walls and roofs, compare bolt displacements in different geological contexts and stress environments, and monitor the rock mass and ground support response to stope and development blasts. The impact of bolt spacing and bolt type on rock surface deformation was also measured. Testing of the technology to date has demonstrated clear value and has the potential to assist ground control engineers by providing visual records and quantitative assessments of rock mass deformation and ground support performance. Advanced deformation monitoring can be a valuable asset for optimising ground support design and monitoring ground support performance.
\end{abstract}

Keywords: rock mass deformation, monitoring, ground support, GML, LiDAR

\section{Introduction}

The development of the Geotech Monitoring LiDAR (GML) Underground is intended to provide portable, fast and highly accurate deformation measurements combined with a front-end software toolbox similar to the one developed by GroundProbe for open pit radar monitoring. The purpose of the project and extended trial was to assess whether underground deformation monitoring could eventually lead to improvements in ground support selection and performance assessment, the identification of vulnerable areas and generally complement the monitoring toolbox currently available to ground control engineers at Agnico Eagle Mines Limited (AEM).

The GML system, developed by GroundProbe, is a technology for periodic or continuous monitoring of surface displacements that can be used to measure the rock mass and ground support response under mining conditions. Compared with point measurement monitoring, the GML system provides quantitative data on not only the performance of a single bolt unit but also its general performance within a global system of support. The two types of measurements-that is, point measurements inside the rock mass and surface 
deformation measurements - are both useful and complement one another. The GML system uses 3D light detection and ranging (LiDAR) to generate a million point cloud that is processed by GroundProbe's SSR signal processing software. As the SSR system uses interferometric measurements, the precision does not vary when the distance to the target increases. The system has been widely described in several publications (Campbell et al. 2015; Campbell et al. 2017; Dick et al. 2013; Harries et al. 2006). This system was also tested in 2017 at the Kidd operations in a known seismically active area; the results were used to forecast deformation and possible seismic energy release (Counter 2017).

Innovative research in ground monitoring is part of a global initiative within AEM to quantify the response of various ground support systems in use in our operations and eventually to optimise the ground support designs based on a quantitative approach. The objectives of the initiative are to increase understanding of the rock mass response in relation to geology and loading, validate and fine-tune modifications to ground support designs, reduce overall ground support costs and provide ground control engineers with quantitative measures to demonstrate the benefits of proper support installation. The AEM GML project commenced in 2017 with a one-month trial period and then resumed in September 2018 with an extended trial period. Since the beginning of the extended trial period, a total of $201 \mathrm{GML}$ scans have been completed, processed and analysed by AEM Technical Services at the Pinos Altos mine in Mexico (50) and at Goldex mine in Canada (151).

This paper presents the results obtained from four GML stations-two at the Goldex mine and two at the Pinos Altos mine - to illustrate what has been learned from the project. Examples of periodic and continuous scans are presented. Periodic monitoring involves returning to the same location multiple times, whereas continuous scanning is accomplished from a single fixed location over an extended period.

\section{$2 \quad$ Methodology}

\subsection{Geotech Monitoring LiDAR setup and operation}

For periodic monitoring, the GML is positioned on a tripod (Figure 1) and geo-referenced using three to five targets previously installed on the surface of the excavation. Care and precision in the setup allow for higher resolution and fewer errors in the measurements. A good setup takes 10 minutes, and scanning the targets for geo-referencing requires another 10 minutes. The $\mathrm{GML}$ is then ready to start the $360^{\circ}$ scan, during which a high-speed transmitted and reflected laser beam is emitted from the laser scanner. This scanning step lasts seven minutes, during which millions of points are recorded in the 3D space with coordinates relative to the position of the scanner. Finally, the data is transferred to a computer via Wi-Fi in three minutes. The total time for a complete scan from setup to transfer is 30 minutes in total, without processing. Each scan generates a point cloud with a time and date stamp.

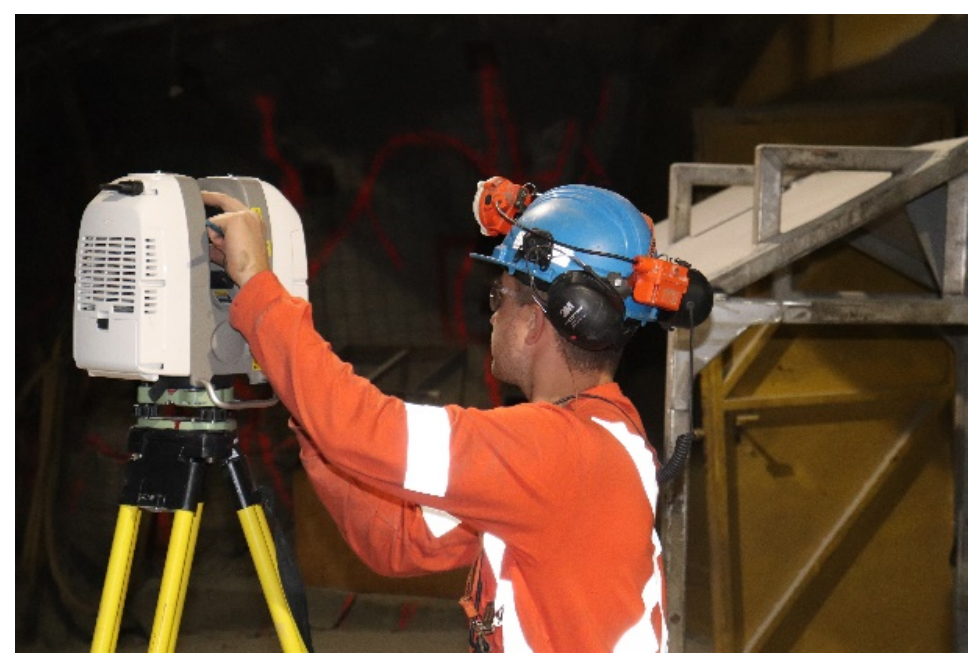

Figure 1 A GML setup at the Goldex underground mine 
The SSR software compares the sequential geo-referenced point clouds and generates a resultant image for deformation analysis. Individual pixels in each of the images generated present either negative or positive deformation with respect to the scanner. The change in position of each pixel can be measured individually or averaged over a region to measure the deformation over different time intervals. The scanner operator records all relevant observations that may influence the data interpretation, such as movement of material in front of the walls; rehabilitation works, including scaling; multiple layers of screens; and angle of incidence. Photographic records from the scanner and the operator are essential for the interpretation of the scanning results. The measured deformations are validated with visual inspections, photographic records and overlapping scans and can be compared with traditional point measurements, such as extensometers, cavity monitoring system (CMS) scans or convergence measurement systems. Consistency, attention to detail and speed of execution onsite are essential because the scanning is done in production areas and must be as unobtrusive as possible.

\subsection{Test sites and geology context}

\subsubsection{Goldex mine}

The Goldex mine is an underground bulk mining gold operation located near the town of Val-d'Or in the Abitibi region of north-western Quebec, Canada. The Goldex deposit is hosted in a diorite sill intruded within a package of mafic to ultramafic rocks. Late stage diabase dykes, of variable thickness, crosscut all the lithologies (Figure 2a). The ore is associated with quartz tourmaline veining in the diorite sill. Ore zones shown in Figure $2 b$ include the GEZ Zone, which was partially mined from 2009 to 2011; the M and E Zones, which were started in 2013; and the Deep Zones (D1 and D2). The bulk of the production currently comes from the Deep 1 Zone, and it is hauled to the shaft loading station via a RailVeyor ${ }^{\mathrm{TM}}$.

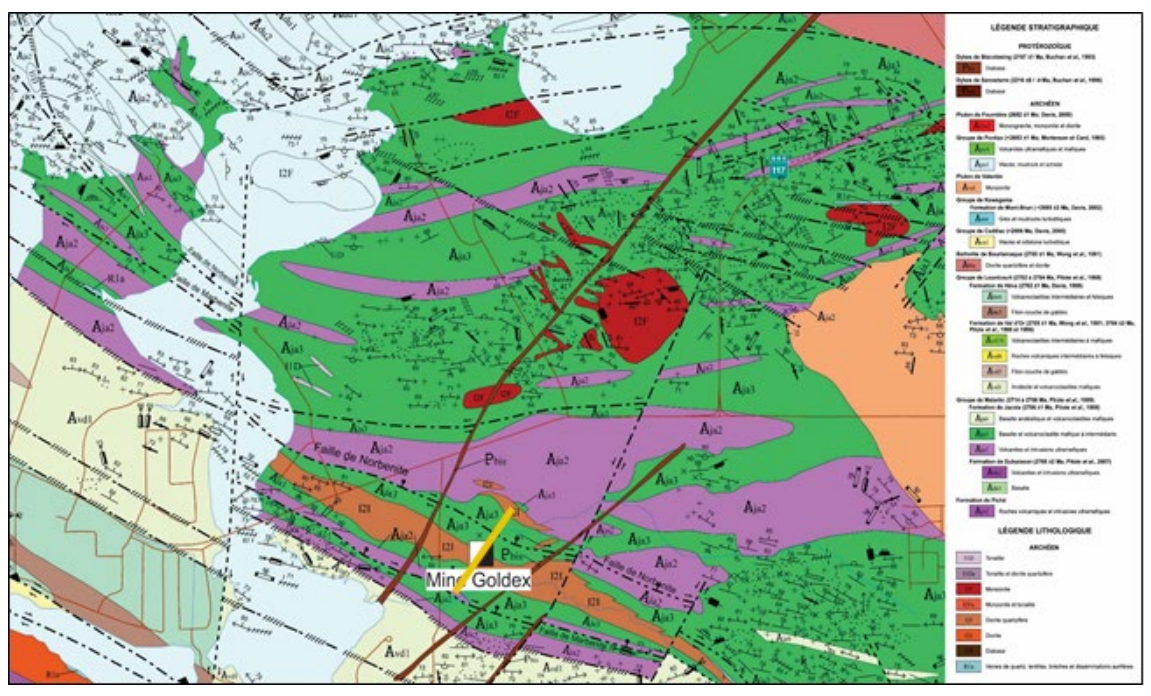

(a)

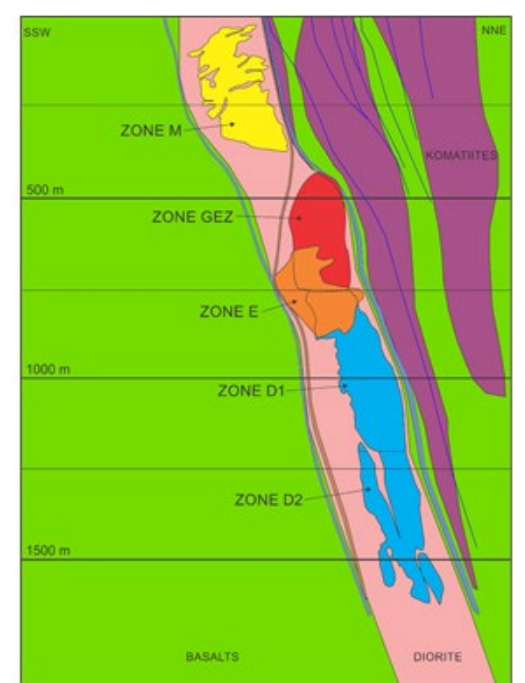

(b)

Figure 2 (a) Regional geology at the Goldex mine; (b) Cross-section showing the geology and different mining zones: GEZ, M and E Zones, and Deep 1 and Deep 2 Zones (AEM 2018)

\subsubsection{Pinos Altos mine}

The Pinos Altos mine is located in the state of Chihuahua in north-western Mexico within the Sierra Madre geologic province (Figure 3a). The Pinos Altos complex includes both open pit and underground operations producing gold and silver. Underground mining, by sublevel stoping with cemented paste backfill, is currently used to extract the ore from the Santo Niño, Cerro Colorado and Oberon de Weber deposits. Satellite deposits Sinter and Cubiro are presently under development. The Santo Niño, Oberon de Weber and Cerro Colorado orebodies are associated with the Santo Niño Fault system, a $300 \mathrm{~km}$ long west-northwest trending structural zone (AEM 2007). The host rocks are young (<38 Ma) compared with Canadian Shield rocks at 
Goldex ( 2,700 Ma), and the in situ stress regime is related to normal faulting. Gold and silver mineralisation at Pinos Altos is in low-sulphidation epithermal-type hydrothermal quartz veins, stockworks and breccias. Santo Niño mineralisation occurs in the footwall of the Santo Niño Fault within open-spaced breccia and stockwork. The hanging wall (south) and footwall (north) of the fault are respectively composed of the Buenavista ignimbrite and Victoria ignimbrite (Figure $3 \mathrm{~b}$ ). The Victoria ignimbrite is composed of vitrocrystalline and lithic tuffs of rhyolitic to dacitic composition, aphanitic tuffs, pyroclastic lithic tuffs and volcanic breccias. The Buenavista ignimbrite is a series of dacite to rhyolitic pyroclastics. The Santo Niño andesite is an intrusive unit that has intruded along the Santo Niño Fault zone, and it is found in close association with the Santo Niño Fault. Clay alteration is pervasive in some lithological units of the Buenavista Ignimbrites and is encountered locally and in joint infilling in the Victoria Ignimbrites.

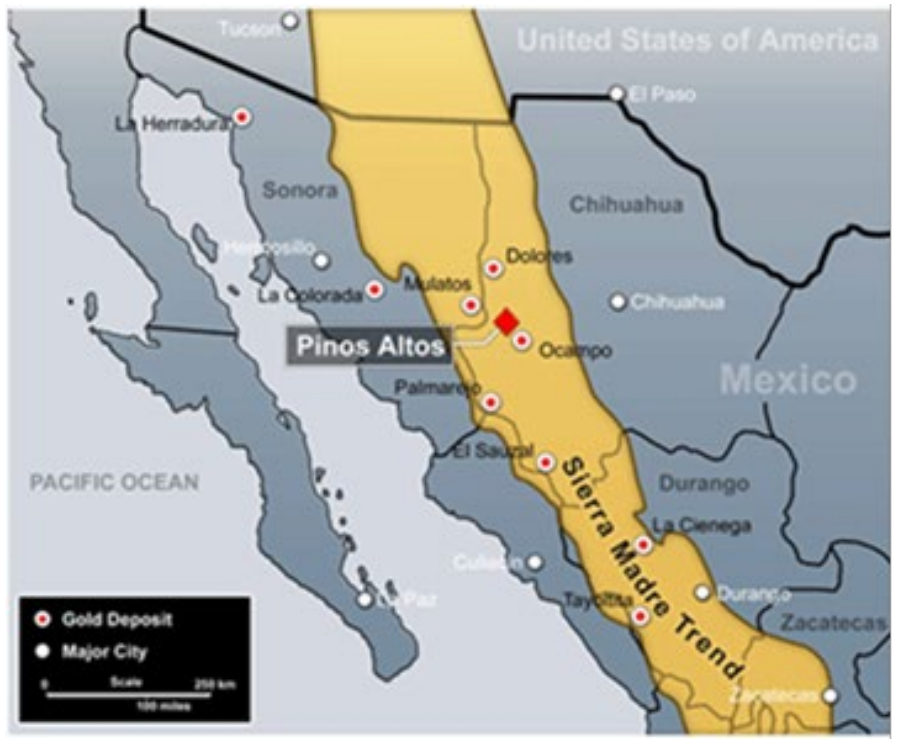

(a)

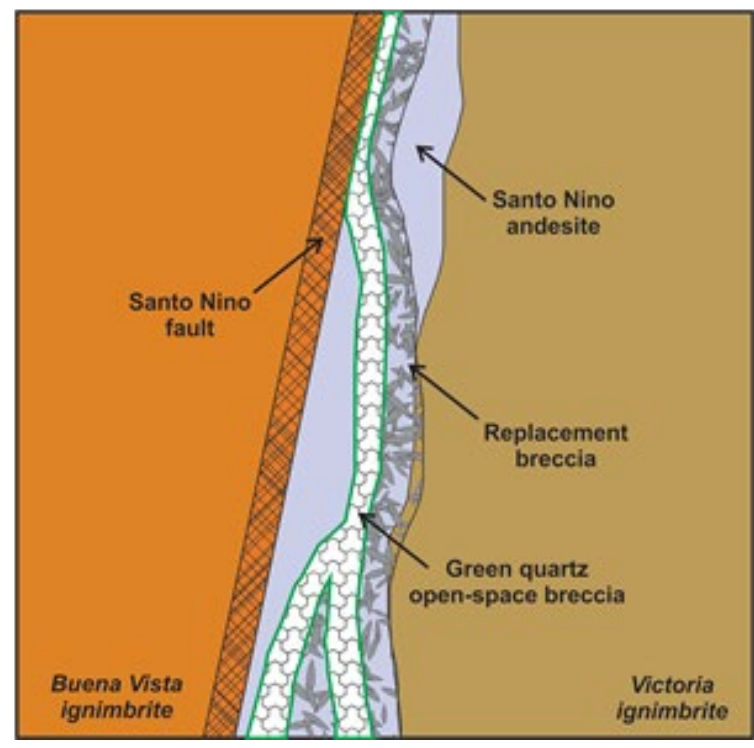

(b)

Figure 3 (a) Location of the Pinos Altos mine in Mexico; (b) Cross-section showing the geological units at the Santo Niño orebody (AEM 2007)

\section{$3 \quad$ Field results and interpretation}

\subsection{Goldex GL11507 (top of longhole stope-periodic scanning)}

The GML station was set up within the overcut in front of a secondary stope at a depth of 1,150 m. Figure 4a shows a plan of the scan location in front of the future Stope $120-129 \mathrm{C}$ and the backfilled primary stopes on either side. During the monitoring period, activities included the backfilling of Stope 115-128D and blasting of Stope 120-129C. Figure $4 \mathrm{~b}$ shows the complete primary ground support and cable-bolting pattern in the stope overcut. Double bulge cable bolts in the stope backs are tensioned and plated. The deformation response of each type of ground support element was measured and analysed over a series of periodic scans from the same location, identified as GL11507.

Table 1 presents a summary of the scanning and mining activities related to this GML station: the dates of the GML scans, the three blasts in 120-129C and the backfilling of the adjacent Stope 115-128D. 


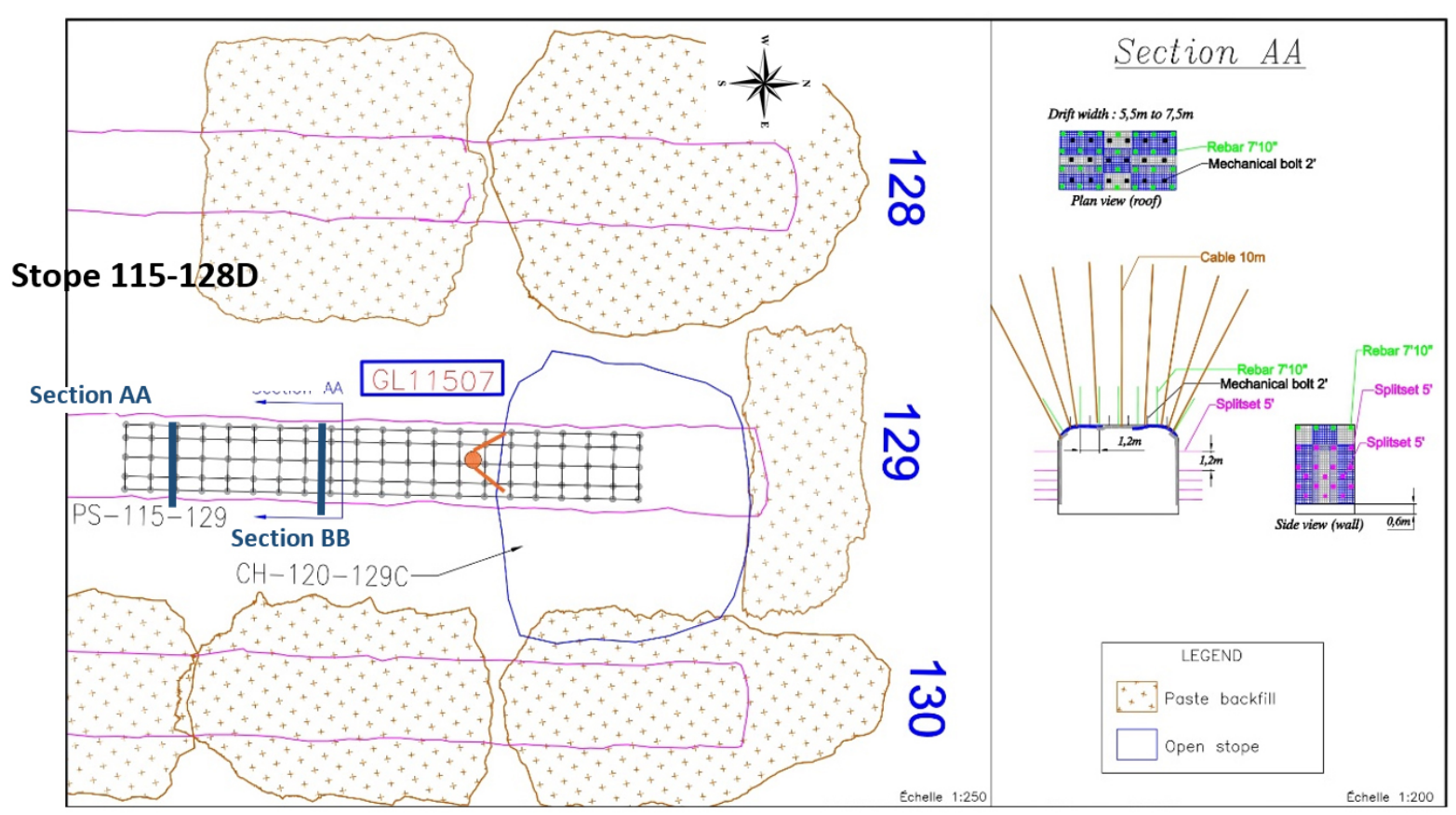

Figure 4 Position of the GML station GL11507 on plan with a cross-section showing the ground support and cable-bolting pattern in the Stope 120-129C overcut on Level 115. Sections AA and BB are referenced on this plan

Table 1 Summary of scanning- and mining-related activities near the GML station GL11507

\begin{tabular}{ll}
\hline Date & Events \\
\hline 30 January 2019 & $360^{\circ} \mathrm{GML}$ scan \#1 \\
6 February 2019 & $360^{\circ} \mathrm{GML}$ scan \#2 \\
11 February 2019 & Start backfilling of adjacent Stope 115-128D \\
14 February 2019 & $360^{\circ} \mathrm{GML}$ scan \#3 \\
15 February 2019 & Blast \#1 of 9,000 tons in Stope 120-129C \\
17 February 2019 & End backfilling of adjacent Stope 115-128D \\
20 February 2019 & $360^{\circ} \mathrm{GML}$ scan \#4 (am) and blast 18,000 tons (pm) in 120-129C \\
7 February 2019 & Final blast of 23,000 t in 120-129C \\
7 March 2019 & $360^{\circ} \mathrm{GML}$ scan \#5 \\
15 March 2019 & $360^{\circ} \mathrm{GML}$ scan \#6 \\
\hline
\end{tabular}

After the backfilling of Stope 115-128D had commenced, it was noticed that the west wall and bolts in the 115-129 drawpoint showed a higher rate of deformation than the east wall. This effect was also directly linked with the observation of water draining through the west wall. As backfilling continued in Stope 115-128D, water could be observed draining through the pillar with the Stope 115-128D into the drive where the GML station is located. Figure 5 shows the measured deformation between 30 January and 20 February, before the first blast of the Stope 120-129C. As there was no blast-induced stress change during this period, the observed positive deformation of approximately $10 \mathrm{~mm}$ is related to the transient water pressure within the drawpoint pillar. Hot colours in the images represent positive deformations with the wall moving towards the scanner. Cold colours indicate negative deformations and are related to loss of material from the wall surface. 


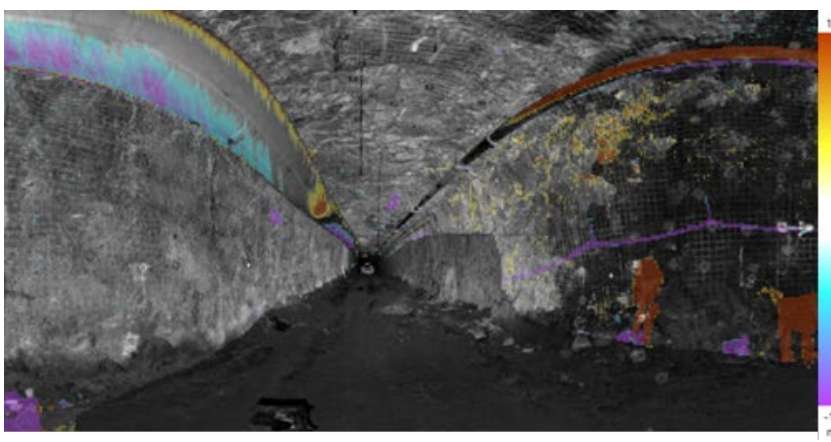

(a)

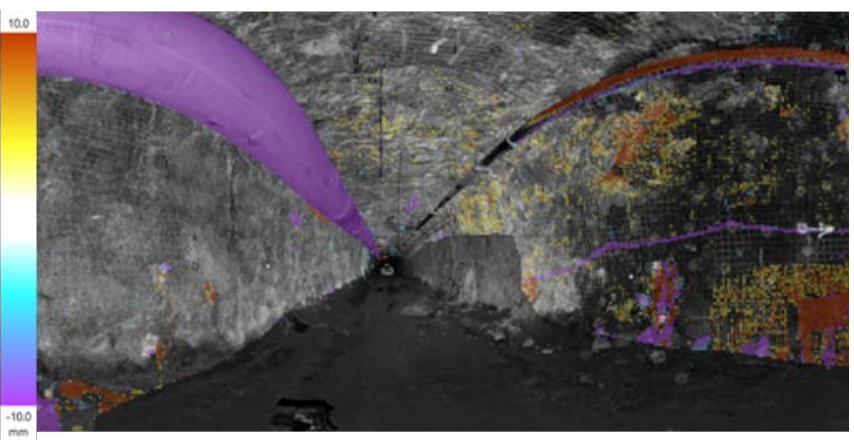

(b)

Figure 5 Section of a $360^{\circ}$ scan at the station GL11507. The image represents the total deformation measured between 30 January and 14 February 2019 (a), and between 30 January and 20 February 2019 (b). The scale of deformation is in millimetres and the same for both images

Figure 6 shows the location of the point measurements that were selected on the walls and roof to track the deformation history of the excavation over the entire duration of the scans conducted at this station from 30 January to 15 March 2019. As repeated scans were conducted at this station, the measurement points had to be carefully selected to avoid obstruction of cables, pipes, machinery and fences and to avoid multiple screen overlap. Two Split Sets were chosen in each wall, one wall measurement and three bolts on the roof.

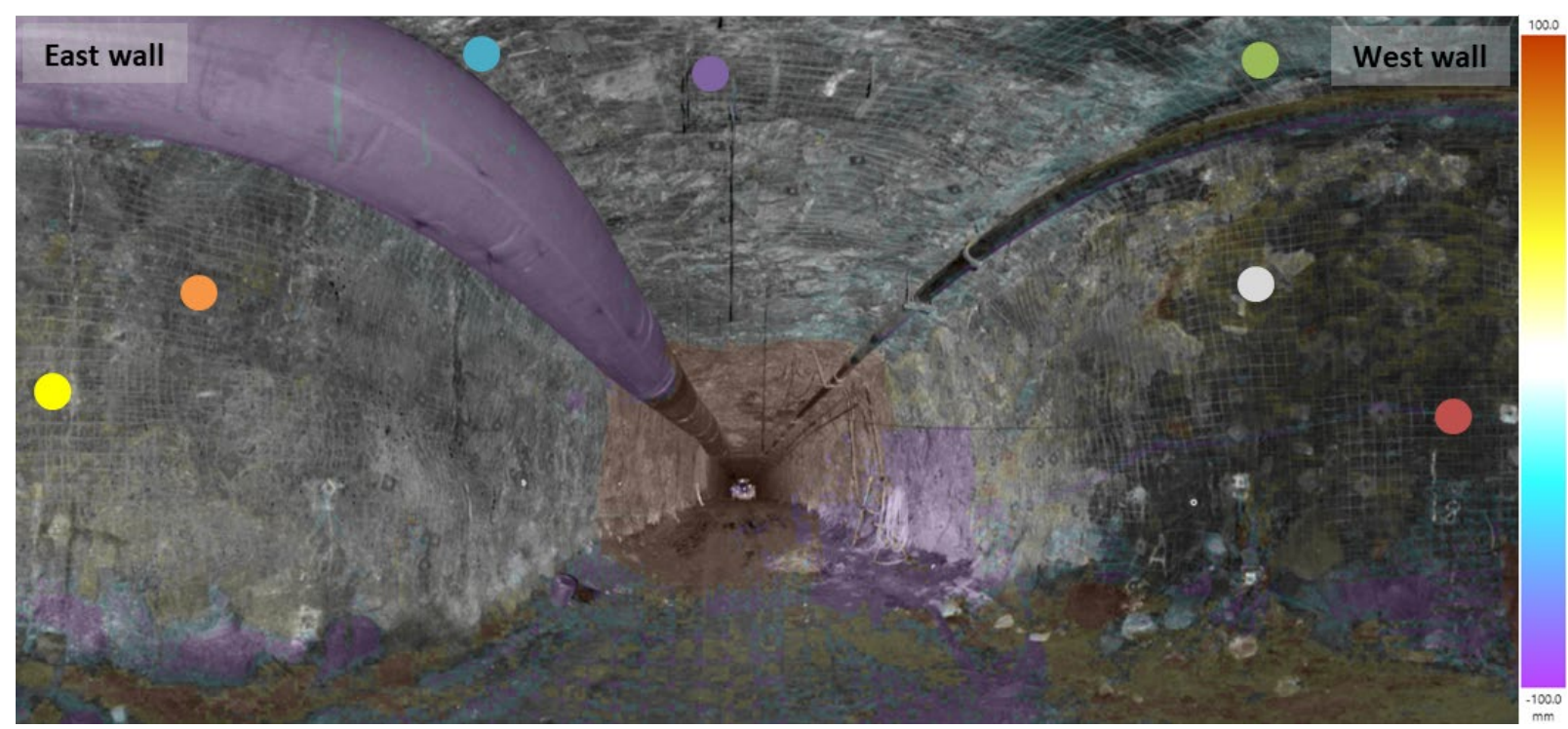

Figure 6 Section of a $360^{\circ}$ scan of the station GL11507. The points in the photograph are located on Section AA in Figure 4. This image represents the total deformation measured between 30 January and 15 March 2019, with the deformation scale in millimetres. Note the scale is 10 times that in Figure 5

Figure 7 shows a graph of the deformation history of the bolts and wall surfaces at the locations identified in Figure 6. The scans concur with visual field observations that the west wall deformed more than the east wall. Examination of Figure 7 shows that the west wall of the drive clearly deforms significantly more than the east wall on the selected section and there is a step change in deformation with the third and last blast in Stope 120-129C. The last scan, more than two weeks later, shows no further deformation post-blast. 


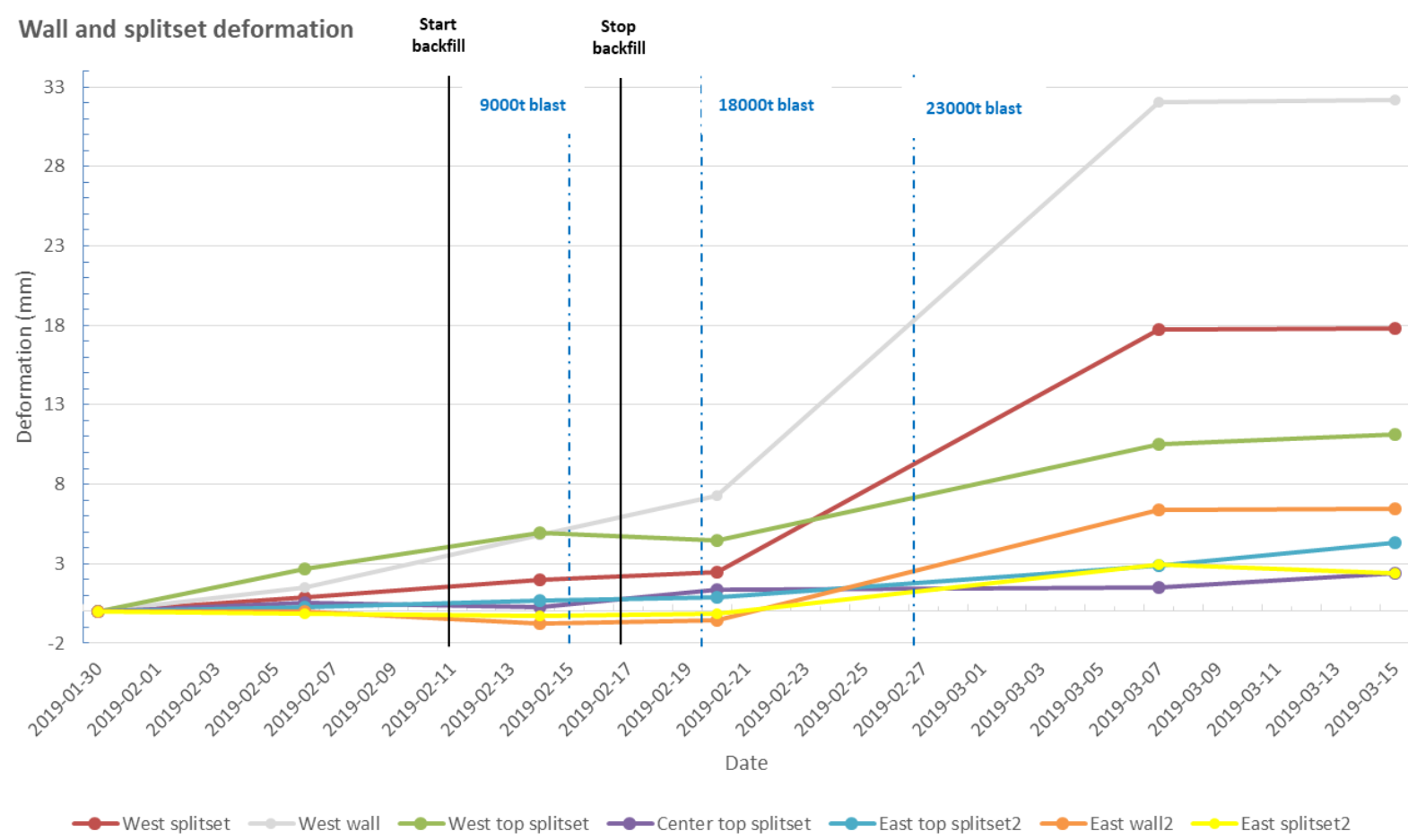

Figure 7 Graph showing wall and Split Set deformation with times at the locations indicated in Figure 5

Table 2 Deformation measurement of different points on bolts or wall since the beginning of scanning on 30 January 2019-referring to section BB

\begin{tabular}{llll}
\hline Scan on 20 February 2019 & & \multicolumn{2}{l}{ Scan on 7 March 2019 } \\
\hline Cable bolt 1 (east) & $+0.2 \mathrm{~mm}$ & Cable bolt 1 (east) & $+0.5 \mathrm{~mm}$ \\
Cable bolt 2 (centre) & $+0.5 \mathrm{~mm}$ & Cable bolt 2 (centre) & $+1.0 \mathrm{~mm}$ \\
Cable bolt 3 (west) & $+0.0 \mathrm{~mm}$ & Cable bolt 3 (west) & $+1.0 \mathrm{~mm}$ \\
East Split Sets down & $+6.6 \mathrm{~mm}$ & East Split Sets down & $+40.0 \mathrm{~mm}$ \\
East Split Sets middle & $+4.4 \mathrm{~mm}$ & East Split Sets middle & $+14.0 \mathrm{~mm}$ \\
East Split Sets top & $+2.7 \mathrm{~mm}$ & East Split Sets top & $+8.2 \mathrm{~mm}$ \\
East wall middle & $+3.7 \mathrm{~mm}$ & East wall middle & $+27.0 \mathrm{~mm}$ \\
East wall up & $+2.1 \mathrm{~mm}$ & East wall up & $+17.0 \mathrm{~mm}$ \\
Roof (centre) & $-2.4 \mathrm{~mm}$ & Roof (centre) & $-13.0 \mathrm{~mm}$ \\
West wall middle & $-1.5 \mathrm{~mm}$ & West wall middle & $+30.0 \mathrm{~mm}$ \\
West wall up & $-1.1 \mathrm{~mm}$ & West wall up & $+29.0 \mathrm{~mm}$ \\
West Split Sets down & $+1.0 \mathrm{~mm}$ & West Split Sets down & $+18.0 \mathrm{~mm}$ \\
West Split Sets middle & $0.0 \mathrm{~mm}$ & West Split Sets middle & $+30.0 \mathrm{~mm}$ \\
West Split Sets top & $-1.0 \mathrm{~mm}$ & West Split Sets top & $+5.0 \mathrm{~mm}$ \\
\hline
\end{tabular}

Table 2 presents measurement points selected close to Stope $120-129 \mathrm{C}$ and located on Section BB from Figure 4; positive values indicate movement into the drift while negative values indicate movement away from the drift. The deformation results presented in Table 2 were obtained by subtracting the fourth and the fifth scans from the first scan. These fourth and fifth scans are of interest because they were taken before and after the last blast of the secondary Stope 120-129C, at the overcut Level 115 . The cable bolts in the roof 
of the stope show no deformation after the first 9,000 $t$ blast and showed only small but detectable deformation after the stope was completed. The Split Sets on the east wall clearly indicate the deformation induced with the last stope blast. There is more deformation in the lower row of bolts compared with the middle and top rows of bolts. In the roof, several areas above the stope showed small negative deformation, which is attributed to damaged mesh from the projection of rocks during each blast. The west wall deformation is generally in the same range as the east wall deformation, which is different from the measurements obtained along Section AA.

The results of the scans in drawpoint 115-129 illustrate the stress and deformation history experienced by a secondary access due to stope blasting and the effect on the overcut drawpoint pillars of water infiltration from the backfilling of an adjacent primary stope.

\subsection{Goldex GL11508 (muck barricade-continuous scanning)}

A continuous monitoring station was set up in front of a $12 \mathrm{~m}$-long muck barricade built to retain paste backfill during the curing period. The stope that was backfilled is the $115-128 \mathrm{D}$ presented in Figure 4 . The stope was continuously backfilled at an average rate of 350 metric tonnes per hour with a recipe of $3 \%$ binder ( $80 \%$ slag and $20 \%$ general use cement) for a total of 6 days. Problems at the paste plant caused a stoppage in the backfill requiring a $45 \mathrm{~m}^{3}$ water flush shortly after start-up. The monitoring period extended over 18 hours after the beginning of the pour. A scan was made every hour for a total of 17 scans. The results of the scans confirmed that the barricade is well built and that it does not move significantly during the pour. Examination of sequential scans and images prompted a more detailed analysis. Figure 8 shows three different locations selected for tracking the deformation (with an area $\pm 0.1 \mathrm{~m}^{2}$ ) directly on the muck barricade and one in the centre of the drainage pond. It was observed from the sequential scans that water was accumulating in the pond. Since the water in the pond could freely drain and was undisturbed because access to the drawpoint was closed, a measurement area $\left( \pm 0.1 \mathrm{~m}^{2}\right)$ could be used in the centre of the pond as a proxy to monitor the water draining from the barricade.

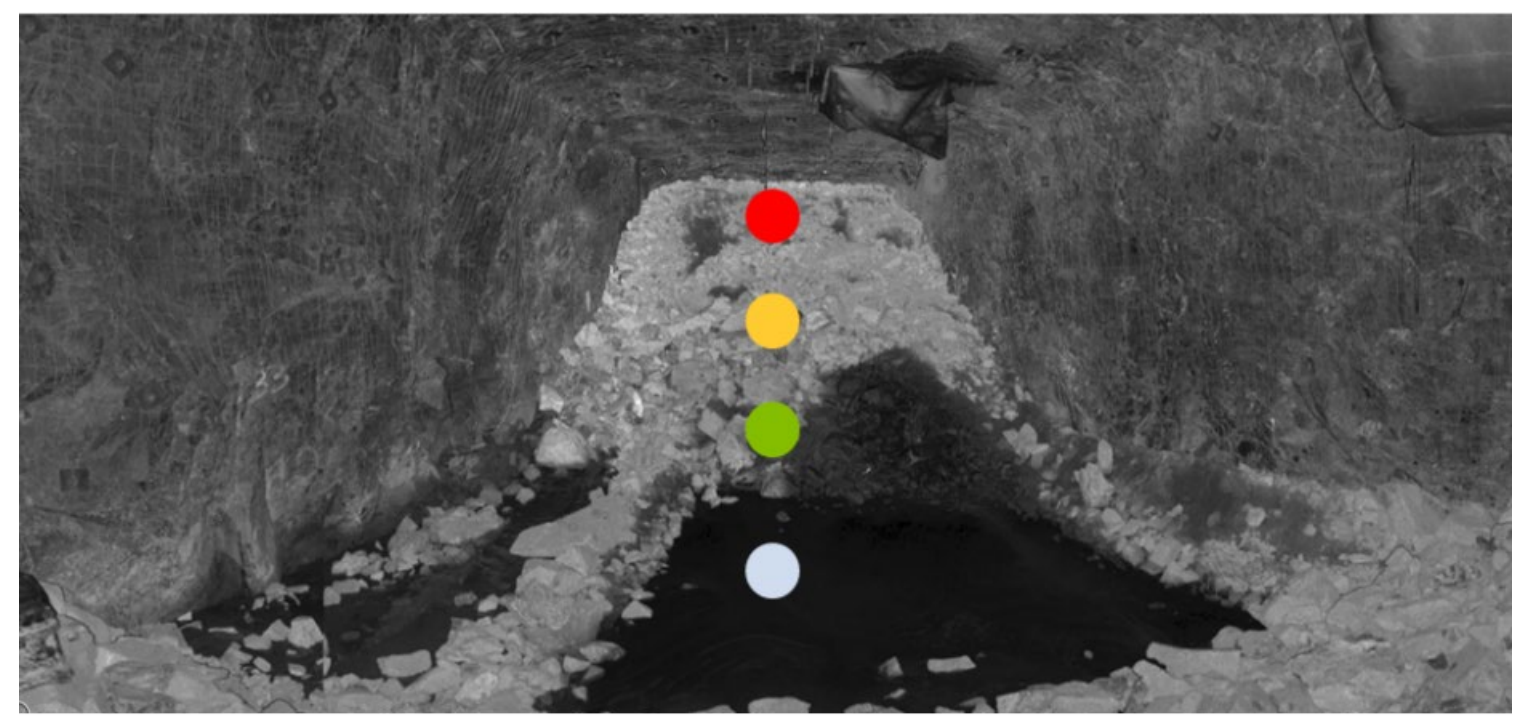

Point of measure-top of the barricade

Point of measure- middle of the barricade
Point of measure-bottom of the barricade

Point of measure-drainage pond

Figure 8 Measurement points on the muck barricade and on the drainage pond

Figure 9 is a plot of the measured deformations at three areas (top, middle and bottom) on the face of the barricade with respect to filling activities and water level in the drainage pond. The deformations are very small, sub-millimetric, confirming that the $12 \mathrm{~m}$ barricade design is effective and no deformation would be noticeable from visual inspection however, assuming that the continuous scan is providing accurate results some additional information may be extracted from the data. The graph shows that the deformation is 
greater in the middle of the barricade compared to the top and bottom, the barricade drains as intended by design, and the early flush of water had a small but nonetheless detectable effect on the central portion of the barricade. After the paste restarted at 19:30, the deformation in the barricade stabilised, the water in the pond rose again and then subsided. The water elevation in the drainage pond does not return to its original level due to the accumulation of fine particles that migrated through the barricade into the drainage pond. The original goal of the continuous scan was to validate the barricade design; however, the results obtained are interesting and motivate further scans with complementary measurements of paste height and more precision on the paste plant data.

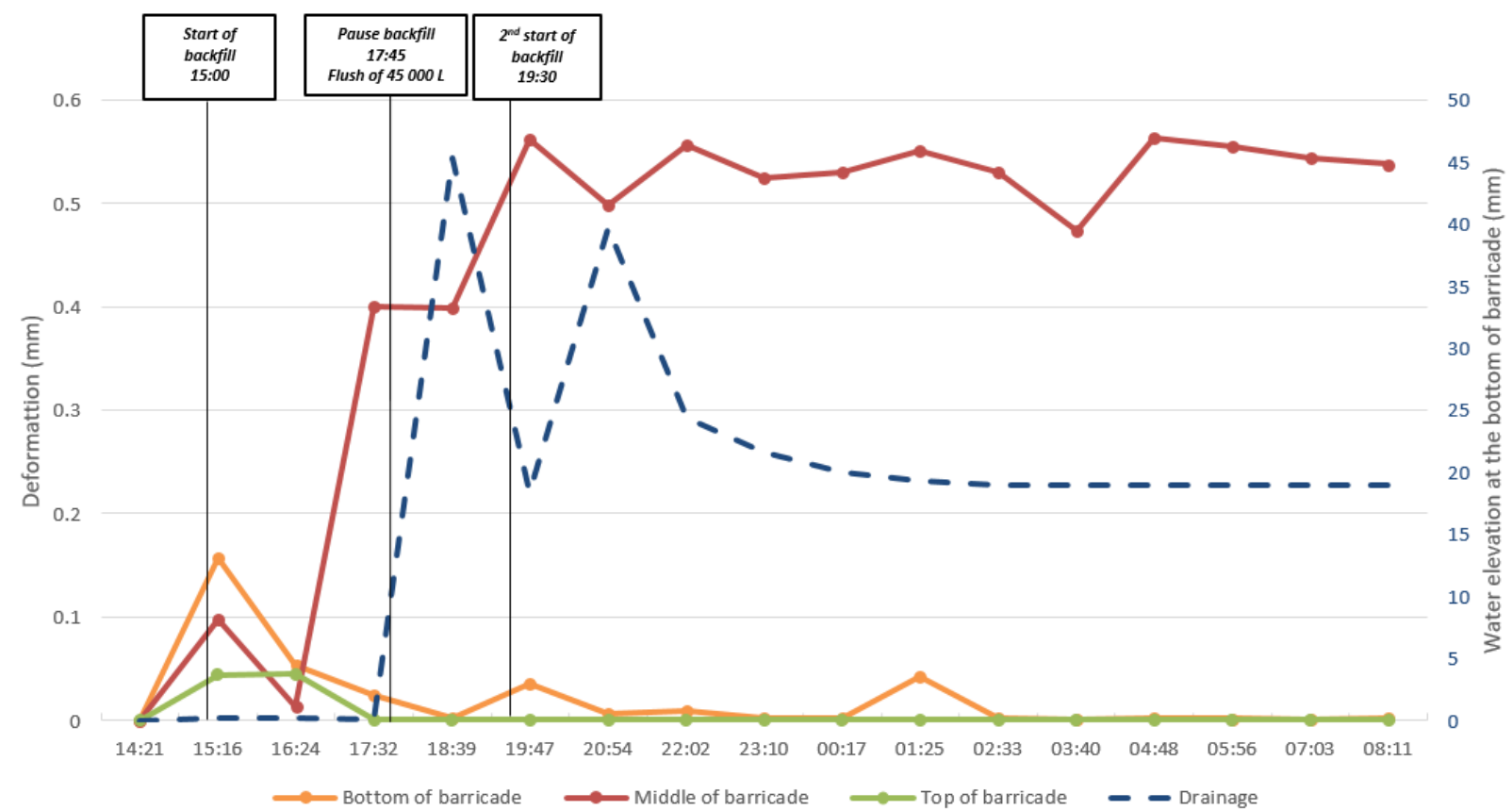

Figure 9 Graph showing the deformation and water elevation measurements in front of the muck barricade

\subsection{Pinos Altos PSN28003 (adjacent to stope blast top drive-periodic scanning)}

A GML station was set up in the adjacent drive to the overcut of a longhole stope blast in SN29056. The station was located to the east of the blast in drawpoint SN28057, as shown in Figure 10. Ground reinforcement in stope overcuts consists of resin-grouted rebar (in waste) or inflatable bolts (in ore) in the roof and Split Sets in the walls. Mesh is used as surface support and cable bolts are installed in the backs of all stopes.

Scans were made before and after the stope blast on 7 December 2018. The deformation induced by the blast in the wall of the adjacent drive is presented in Figure 11. The scanned wall is divided into three sections highlighting the differences between the top, middle and lower parts of the rock surface. In the top third of the wall, the positive deformation varies from $20 \mathrm{~mm}$ to $80 \mathrm{~mm}$. Visual inspection of the results indicates that larger deformations seem to occur between the bolts while the Split Sets appear to be limiting the deformation. Furthermore, the deformation is seen to increase, with the spacing between the bolts and pieces of rock that were already loose behind the mesh before the blast displaced with the vibrations. Finally, some negative deformation (blue and purple) is visible on the image, indicating that pieces of rock smaller than the size of the screen fell through during the blast. 


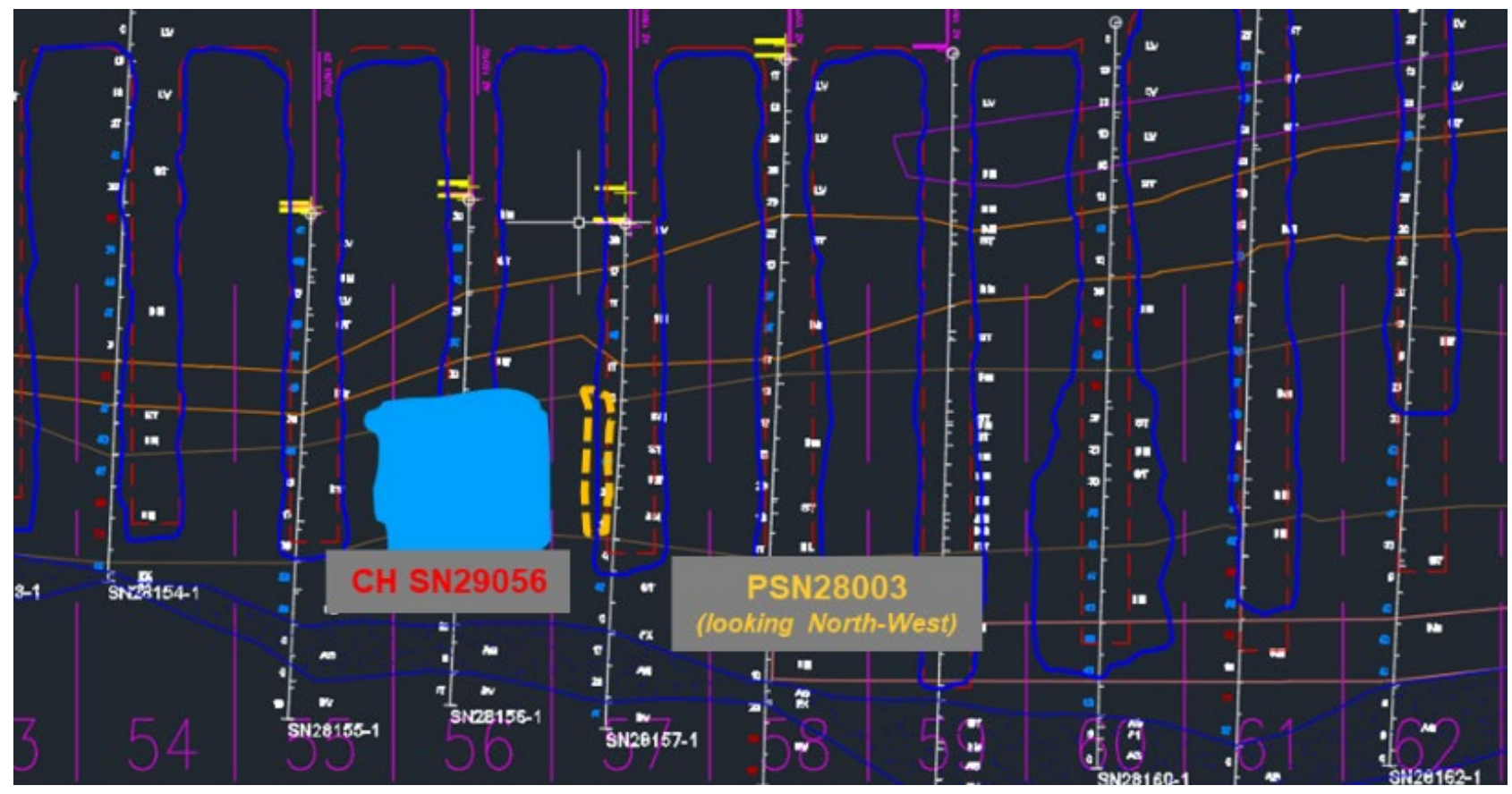

Figure 10 GML station setup in SN28057 to monitor the mass blast in the adjacent Stope SN29056. The $180^{\circ}$ scan targeted the west wall of the drive

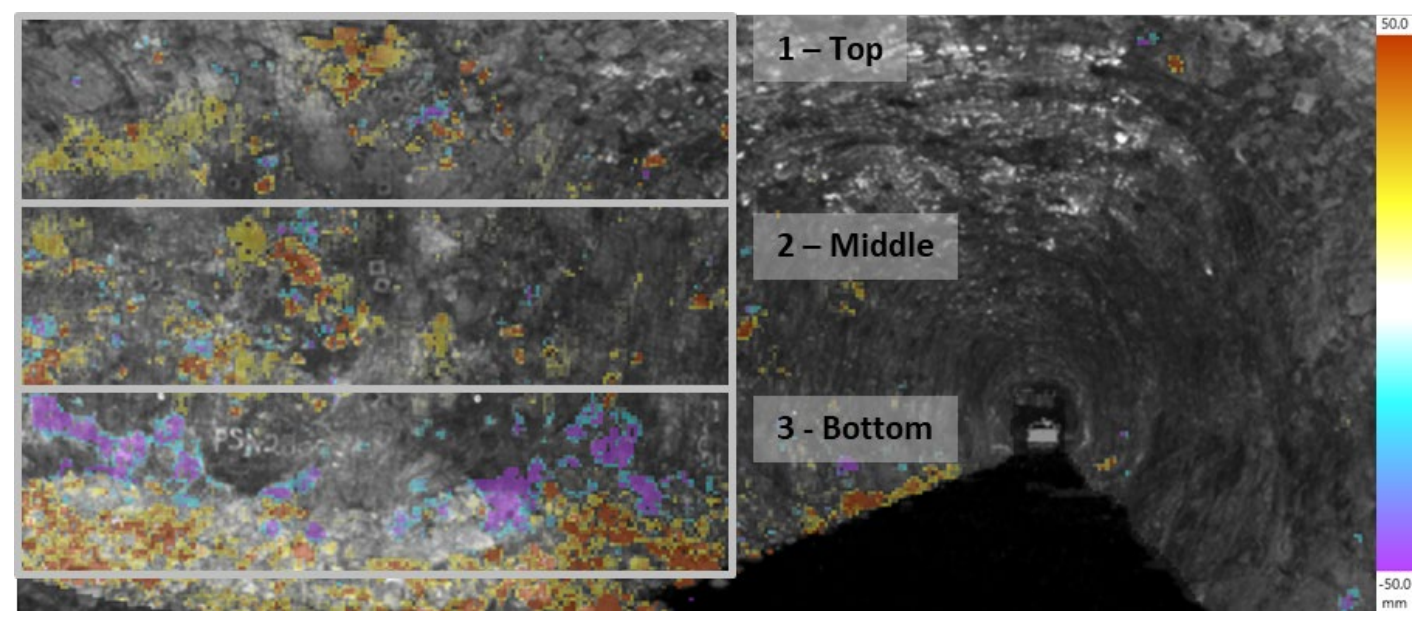

Figure 11 Positive and negative deformation in a drawpoint adjacent to a stope blast on 7 December 2018. The picture date is 8 December, and the image was obtained by subtracting the scans from 8 December and 5 December 2018

The middle section of the wall experienced larger deformations than did the top third. This may be related to the stress regime, the increased confinement in the drift corners compared with the flat wall surface, and/or the effect of the rebar or inflatable bolts in the roof and into the drift corners compared with Split Sets only in the walls. The larger deformations are again observed to occur preferentially between the bolts. On the lower section of Figure 11, the deformation is mostly negative (averaging $30 \mathrm{~mm}$ ) on the wall itself and positive on the floor. This phenomenon is observed in nearly all the GML scans; below the last row of bolts, pieces of rock are seen to detach from the wall with either a blast or seismic events and accumulate at the bottom of the wall. It is important to note that the GML measures deformation at the surface of the excavation; therefore, loose pieces of rock retained by the mesh, as shown in Figure 12 for example, can mask the deformation and affect the results. Loose material is frequently seen to accumulate behind the mesh at Pinos Altos (Figure 12). The phenomenon is attributed to a combination of factors, including the rock mass weathering characteristics, drift blasting practices and ground support selection and installation quality (bolt installation and mesh characteristics). As the mine continues to progress deeper, and conditions 
become less forgiving, there is increasing interest in improving excavation quality and ground support performance. The GML measurement campaigns can assist the mine in this process.

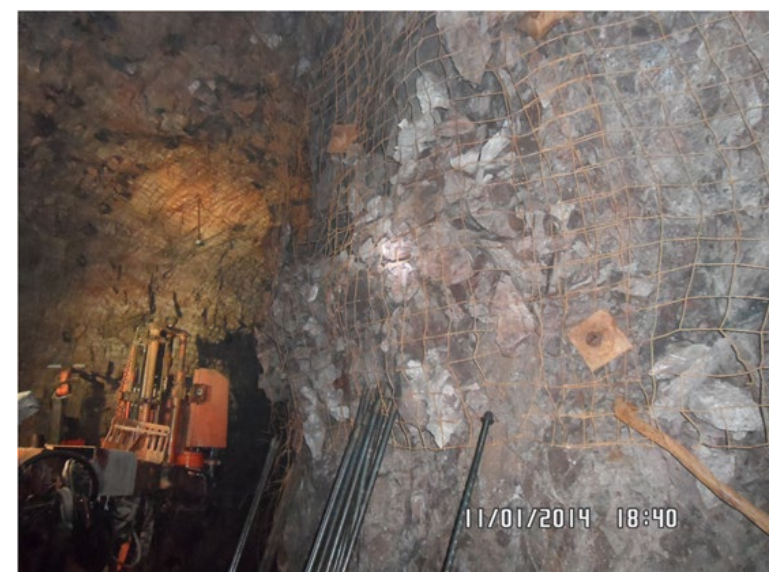

Figure 12 Example of loose material accumulating behind the mesh at the Santo Niño mine. The phenomenon is frequently observed at the site and is attributed to a combination of factors

To assess and quantify the ground support effectiveness in response to the blast, the results were analysed by zones, as shown in Figure 11 and compiled in Figure 13 and Table 3. The wall deformation measurements are averaged from pixels within a consistent $\pm 0.1 \mathrm{~m}^{2}$ area (approximately $30 \mathrm{~cm} \times 30 \mathrm{~cm}$ ), whereas the bolts measurements are averaged over consistent areas of $\pm 0.01 \mathrm{~m}^{2}$ (approximately $10 \mathrm{~cm} \times 10 \mathrm{~cm}$ or roughly the size of a bolt plate). A similar approach of averaging the deformation over a fixed area is used with the radar and SSR software in open pits to reduce the effect of local deformations and obtain an overall rate of deformation for areas of interest (Kalenchuk et al. 2018).

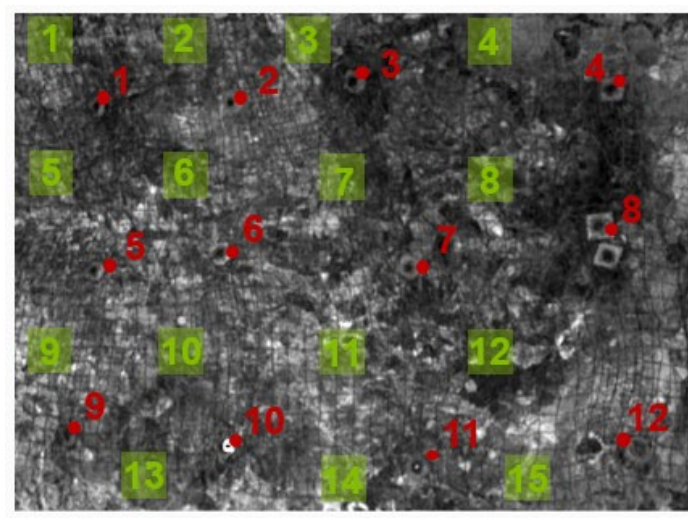

(a)

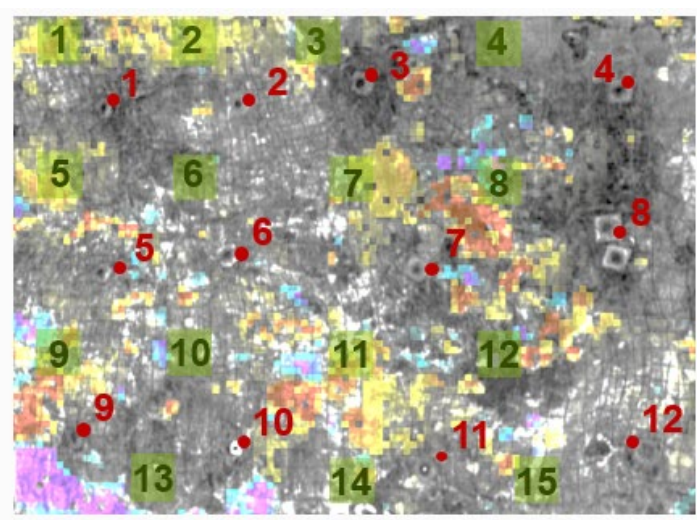

(b)

Figure 13 Zoom-in of the wall image in Figure 11, showing the top and middle sections only. For reference, Bolt 8 (with two bolts side by side) can be seen in the middle section of Figure 11. (a) Photograph with the selected areas; (b) The scan results

Table 3 shows that the average deformation of the split set bolts is about $+2.0 \mathrm{~mm}$, and the absolute average deformation for the wall between the bolts varies between $+2.5 \mathrm{~mm}$ and $+60 \mathrm{~mm}$. Negative deformation representing rocks falling from behind the mesh can reach $-15 \mathrm{~mm}$. The average deformation of the top-row bolts (Bolts 1, 2, 3 and 4 ) is $+1.8 \mathrm{~mm}$, whereas the average rock mass deformation above the bolts (Wall 1, 2, 3 and 4 ) is $+10.3 \mathrm{~mm}$. By comparison, the middle row of bolts (Bolts 5, 6, 7 and 8) moved on average $+2.3 \mathrm{~mm}$. The wall above the middle row of bolts moved on average $+21 \mathrm{~mm}$ (Wall 5, 6, 7 and 8). Below the middle row of bolts, Wall 9 recorded negative deformation of $-10 \mathrm{~mm}$, but on average, the other three areas (Wall 10, 11 and 12 ) displaced by $+13 \mathrm{~mm}$. It is possible that some rock fell below the entire middle row of bolts. Finally, the last row of bolts (Bolts 9, 10, 11 and 12) moved by $+2.3 \mathrm{~mm}$, and all wall deformation was negative, averaging $-10 \mathrm{~mm}$ (Wall 13, 14 and 15). 
Table 3 Bolts and wall deformation compiled from the results shown in Figure 13

\begin{tabular}{llllllll}
\hline \multicolumn{5}{l}{ Split Sets bolts (red points) } & \multicolumn{5}{c}{ Wall (green rectangle) } \\
\hline 1 & $+2.0 \mathrm{~mm}$ & 9 & $+2.5 \mathrm{~mm}$ & 1 & $+16.0 \mathrm{~mm}$ & 9 & $-10.0 \mathrm{~mm}$ \\
2 & $+2.5 \mathrm{~mm}$ & 10 & $+2.0 \mathrm{~mm}$ & 2 & $+16.0 \mathrm{~mm}$ & 10 & $+12.0 \mathrm{~mm}$ \\
3 & $+2.0 \mathrm{~mm}$ & 11 & $+2.5 \mathrm{~mm}$ & 3 & $+6.0 \mathrm{~mm}$ & 11 & $+12.0 \mathrm{~mm}$ \\
4 & $+0.6 \mathrm{~mm}$ & 12 & $+2.0 \mathrm{~mm}$ & 4 & $+3.0 \mathrm{~mm}$ & 12 & $+15.0 \mathrm{~mm}$ \\
5 & $+2.5 \mathrm{~mm}$ & - & - & 5 & $+20.0 \mathrm{~mm}$ & 13 & $-12.0 \mathrm{~mm}$ \\
6 & $+2.5 \mathrm{~mm}$ & - & - & 6 & $+2.5 \mathrm{~mm}$ & 14 & $-15.0 \mathrm{~mm}$ \\
7 & $+3.0 \mathrm{~mm}$ & - & - & 7 & $+1.5 \mathrm{~mm}$ & 15 & $-3.0 \mathrm{~mm}$ \\
8 & $+1.0 \mathrm{~mm}$ & - & - & 8 & $+60.0 \mathrm{~mm}$ & - & - \\
\hline
\end{tabular}

It is possible to use the SSR software to measure the effectiveness of the bolting pattern by measuring the deformation in the area between bolts. The measured bolting pattern in the scanned area varied from $0.74 \mathrm{~m}^{2}$ to $1.48 \mathrm{~m}^{2}$ and the higher wall deformations can be associated with the wider bolting pattern; however, the differences can also be attributed to geological factors. Figure 14 was generated using image treatment in the SSR viewer software to modify the opacity, brightness and contrast in order to highlight differences in the rock mass alteration pattern. With the image treatment, the alteration halos become more visible, enabling them to be used to measure the deformation in relation to the geology. The light-coloured alteration shown in Figure 14 is penetrative silicification (green markers), which makes the rock less deformable than the surrounding more clay-rich tuff (red markers).

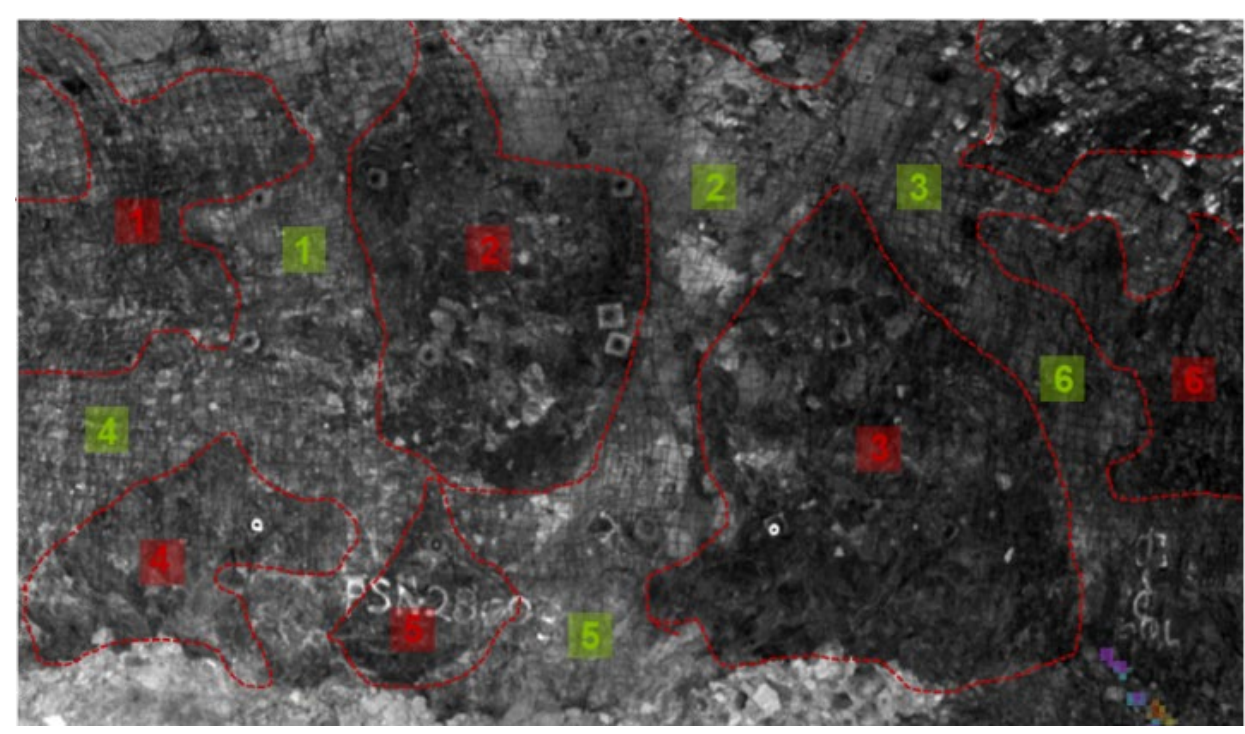

Figure 14 The same scan with enhanced image treatment to highlight the alteration halos contoured in red

The average deformation within the silicification areas is $1.6 \mathrm{~mm}$ compared with $8.5 \mathrm{~mm}$ for the clay-rich tuff. The deformation in the silicification halos is in the same range as that measured for the Split Sets. The detailed measurements are presented in Table 4; positive values are moving into the drift, and negative values indicate movement away from the drift. 
Table 4 Comparison of the wall deformation within and outside the silicification halos

\begin{tabular}{lll}
\hline$\#$ & Wall deformation (red rectangle) & Wall deformation (green rectangle) \\
\hline 1 & $+3.00 \mathrm{~mm}$ & $+1.60 \mathrm{~mm}$ \\
2 & $+20.00 \mathrm{~mm}$ & $-0.12 \mathrm{~mm}$ \\
3 & $+6.00 \mathrm{~mm}$ & $+1.50 \mathrm{~mm}$ \\
4 & $-0.50 \mathrm{~mm}$ & $+4.00 \mathrm{~mm}$ \\
5 & $+2.50 \mathrm{~mm}$ & $+1.50 \mathrm{~mm}$ \\
6 & $+20.00 \mathrm{~mm}$ & $+1.50 \mathrm{~mm}$ \\
\hline
\end{tabular}

These initial scans at the Pinos Altos mine demonstrated the potential for the GML and SSR software to collect and analyse highly informative data to measure the rock mass response to stress change and vibrations, the performance of ground support elements and patterns, and the effect of alteration on rock mass deformation. More scanning data must be collected to continue to validate this potential, but the tests allowed the team to develop new analysis methods and approaches for maximising the benefits extracted from each scan. The $360^{\circ}$ scans were successfully tested at Pinos Altos, and they became the standard after December 2018.

\subsection{Pinos Altos SN315201 (large intersection-periodic scanning)}

The GML station SN315201 was set up to monitor a large intersection on Level 31 (1,550 El) of the Santo Niño orebody at approximately $650 \mathrm{~m}$ below the original ground surface, in front of the drawpoint of Stope SN31052. There were no major developments or stope blasts near this intersection during the two-week interval between scans. Figure 15 shows the results of $360^{\circ}$ scans taken on 6 December and 18 December 2018. A zone of local deformation can be seen in the roof. The deformations on the floors were masked because they are not informative due to equipment traffic.

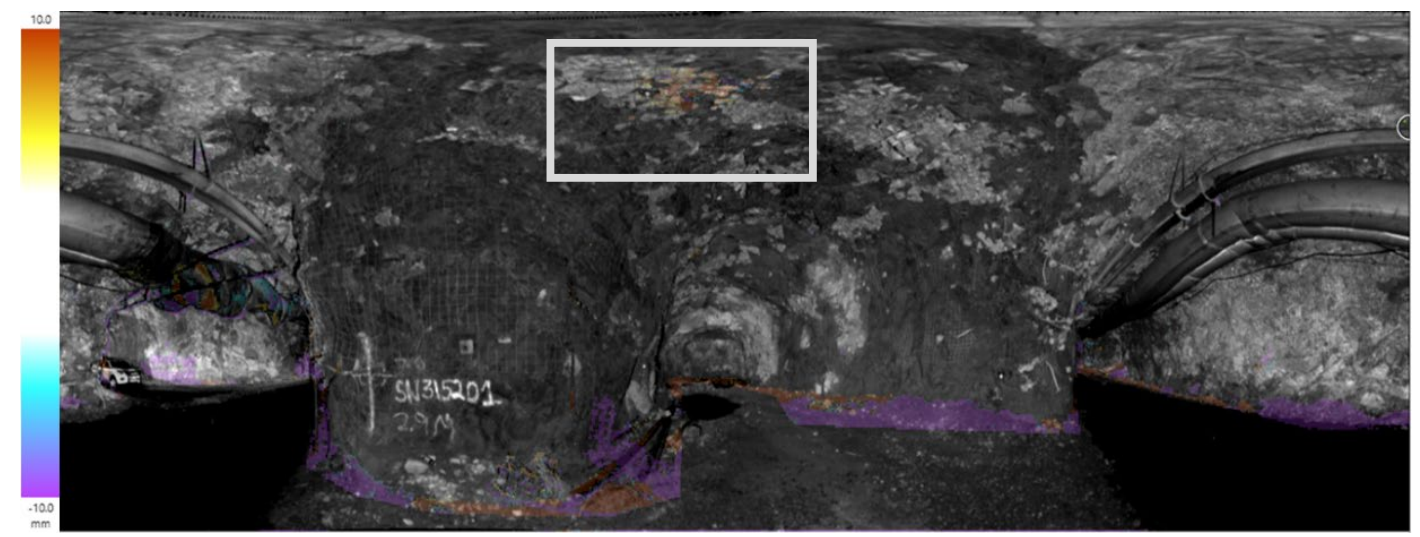

Figure $15360^{\circ}$ scan of the station SN315201; the zone of interest is inside the grey rectangle. This image was obtained from the subtraction of the scans on 18 December and 6 December 2018, with the results shown on the 18 December photograph. The $360^{\circ}$ image is unrolled

Figure 16 is a zoomed-in view of the area of interest, with the measurement points selected for analysis. Within the SSR viewer software, pixels can be selected either individually or grouped to extract deformation measurements. Using this feature, pixels were selected on the ends of the rebar bolts (red points) and within small areas of approximately $0.1 \mathrm{~m}^{2}$ around the bolts. The data is presented in Table 5; positive values are moving into the drift, and negative values indicate movement away from the drift. The maximum positive deformation measured with the scan is $140 \mathrm{~mm}$ on the rock and $40 \mathrm{~mm}$ at the end of the rebar \#3. Upon inspection of the results in Table 5, all bolts except rebar \#3 show minimal deformation, and areas 1, 3 and 4 around rebar \#3 deformed by $80 \mathrm{~mm}$ to $140 \mathrm{~mm}$ around this bolt. By comparison, minimal movement was 
recorded in areas 2 and 5 around bolts that did not move. An underground visual inspection was conducted after the image was generated, and it was clear that the plate of rebar \#3 was loose and not in contact with the rock. Variability in the quality and effectiveness of ground support installation has been observed for some time at Pinos Altos, particularly with respect to hole size, lack of resin encapsulation of the rebars near the hole collars, and loading of the mesh. The exact explanation for the lack of effectiveness of rebar \#3 is not known; the bolt installation may have been inadequate or, less likely, the bolt may have been broken. Nonetheless, the impact of the increased effective support spacing is clear from the measured rock mass deformations, with larger positive deformation (warm colour) and even small rocks detaching from the roof (cold colour).

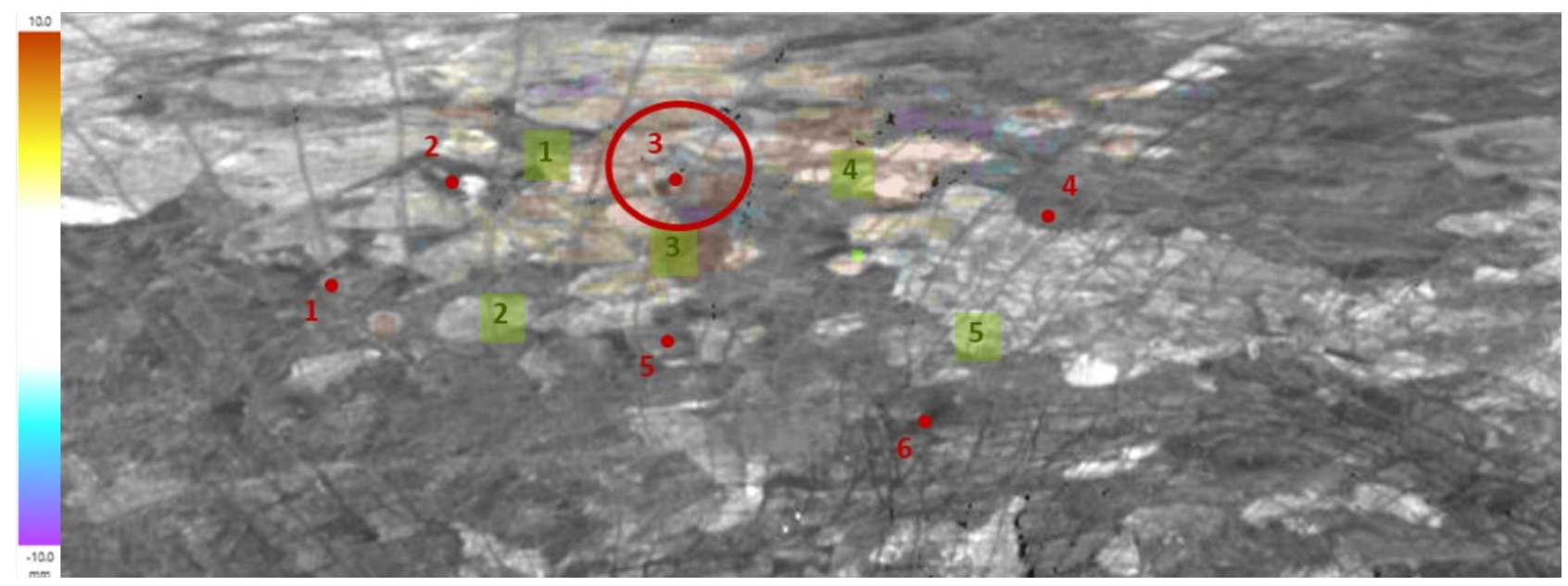

Figure 16 Zoomed-in view from Figure 15 showing area of deformation around an ineffective rebar in the roof

The results of the deformation monitoring are useful for targeting rehabilitation and for communicating to operators and supervisors the importance of ground support installation quality.

Table 5 Rebar and roof deformation in reference to Figure 16

\begin{tabular}{lll}
\hline$\#$ & Rebar bolt (red points) & Wall deformation (green rectangle) \\
\hline 1 & $+0.40 \mathrm{~mm}$ & $+140.00 \mathrm{~mm}$ \\
2 & $+0.05 \mathrm{~mm}$ & $+1.20 \mathrm{~mm}$ \\
3 & $+40.00 \mathrm{~mm}$ & $+80.00 \mathrm{~mm}$ \\
4 & $+0.80 \mathrm{~mm}$ & $+120.00 \mathrm{~mm}$ \\
5 & $+0.60 \mathrm{~mm}$ & $+0.25 \mathrm{~mm}$ \\
6 & $-0.35 \mathrm{~mm}$ & - \\
\hline
\end{tabular}

\section{Conclusion}

The development of new technology and monitoring tools, such as the CMS and radar slope monitoring in open pits, has had a profound and positive impact on the comprehension of rock mass behaviour during mine extraction, safety and improved control of mining practices. Several new technologies are being developed for measuring deformation in the underground environment. Some of the tools proposed are an excellent alternative for rapid and simple-albeit somewhat less precise-scanning on the scale of levels or even mine-wide. Others, such as GroundProbe's GML, are intended for more-precise measurements through frequent periodic or continuous monitoring of specific areas of interest. Both approaches are useful and can provide valuable information. 
Extended testing of the GML and software has been presented with a sample of results from two vastly different operational, geotechnical and geological environments. The GML system was successfully used to measure the rate of deformation at the rock surface and ground support performance through more than 200 scans in many different underground settings. The scan results were used to compare bolt displacements in different geological contexts and stress environments, and to monitor the rock mass and ground support response to stope and development blasts. The effect of bolt spacing and bolt type on rock surface deformation was measured as well as the impact of rock strength-altering alteration on wall deformation. Continuous monitoring allows for higher precision than does periodic scanning. The behaviour of a rock mass barricade was monitored during paste backfilling and during an early water flush against the barricade. The results provided interesting insights and incentive to repeat the monitoring technology in the future. Water infiltration through a pillar during backfilling of an adjacent stope was observed to cause small deformations due to the transient water pressure. The results obtained from Pinos Altos and Goldex mine have demonstrated the potential benefits that can be derived from the application of deformation monitoring technology by a trained field team, coupled with detailed analysis of the results in combination with production events and field observations. The trial conducted in 2017 had also shown potential for relating rock mass deformation with seismic monitoring. The GML system to date has demonstrated clear value and has the potential to assist ground control engineers by providing visual and quantitative assessments of rock mass deformation and ground support performance. Advanced deformation monitoring can be a valuable asset for the optimisation of ground support design and monitoring of ground support performance.

\section{Acknowledgement}

We recognise the contribution of Goldex mine's senior rock mechanics engineer, Chantale Doucet, who has provided technical support, guidance and great ideas throughout the entire process. The project would not have been possible without the support of Chantale and her team as well as the management at Goldex. We wish to express our gratitude to Alfredo Gelover Manzo, ground control engineer, and to Erik Salomón Manríquez Domínguez, ground control technician, from Pinos Altos mine for their interest, support and commitment to this project. For their support, we also wish to thank AEM's technical services vice president, Nancy Guay; the director, Marc Lafontaine; and the engineering superintendent, Josée Cyr. We thank team members who contributed in various ways to the project: Pierre-Olivier Richard, Stéphane Côté, Mathieu Giroux and Serge Boutin of Goldex mine. We acknowledge the commitment of Mr Chris Bijsterveld and the support of GroundProbe's technical and sales teams to the success of this project.

\section{References}

Agnico Eagle Mines Ltd 2018, Internal geology presentation to Goldex GEZ Team, January.

Agnico Eagle Mines Ltd 2007, Pinos Altos Gold Project Feasibility Study, April.

Campbell, L, Cabrejo, AG, Chen, BJ \& Saunders, P 2017, 'A novel geotechnical monitoring technology for underground tunnels to assess ground support effectiveness', Proceedings of the 16th Australasian Tunnelling Conference 2017: Challenging Underground Space-Bigger, Better, More, Engineers Australia, Barton, pp. 187-197.

Campbell, L, Edwards, D, Noon, D, Bellett, P \& Ferdinands, N 2015, 'A new radar technology approach for monitoring high walls and Low walls', in JW Beester (ed.), Bowen Basin Symposium 2015: Bowen Basin and Beyond, GSA Coal Geology Group, Hornsby, pp. 329-338.

Counter, D 2017, 'Strain and rock bursting at Kidd Creek: support response and recent work on damage measurement systems', paper presented at the Strainburst in Mining Seminar - How to Mitigate the Consequences, Sudbury, 10 October 2017.

Dick, GJ, Eberhard, E, Stead, D \& Rose, ND 2013, 'Early detection of impending slope failure in open pit mines using spatial and temporal analysis of real aperture radar measurements', in PM Dight (ed.), Proceedings of the 2013 International Symposium on Slope Stability in Open Pit Mining and Civil Engineering, Australian Centre for Geomechanics, Perth, pp. 949-962.

Harries, N, Noon, D \& Rowley, K 2006, 'Case studies of slope stability radar used in open cut mines', Proceedings of the International Symposium on Stability of Rock Slopes in Open Pit Mining and Civil Engineering, The Southern African Institute of Mining and Metallurgy, Johannesburg, pp. 335-342.

Kalenchuk, L, Falmagne, V, Gelover, A, Montiel, I \& Luzania J 2019, 'Risk evaluation, design, implementation, instrumentation, and verification for crown pillar extraction at Pinos Altos mine,' Rock Mechanics and Rock Engineering, https://dx.doi.org/ 10.1007/s00603-019-01801-z 
